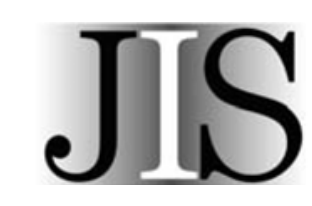

\title{
A bibliometric analysis of pharmacology and pharmacy journals: Scopus versus Web of Science
}

\author{
Juan Gorraiz \\ University of Vienna, Library and Archive Services, Central Library for Physics, Vienna, Austria \\ Christian Schloegl ${ }^{1}$ \\ University of Graz, Institute of Information Science and Information Systems, Graz, Austria
}

\begin{abstract}
Our study aims at examining the suitability of Scopus for bibliometric analyses in comparison with the Web of Science (WOS). In particular we want to explore if the outcome of bibliometric analyses differs between Scopus and WOS and, if yes, in which aspects. In doing so we focus on the following questions: To which extent are high impact JCR (Journal Citation Reports) journals covered by Scopus? Are the impact factor and the immediacy index usually lower for a JCR journal than the corresponding indicators computed in Scopus? Are there high impact journals not covered by the JCR? And, finally, how reliable are the data in these two databases?
\end{abstract}

Since journal indicators like the impact factor and the immediacy index differ among disciplines, we analysed only journals from the subject pharmacy and pharmaceutical sciences. Focussing on one subject category offers furthermore the possibility to go into more detail when comparing the databases.

The findings of our study can be summarized as follows:

- Each top-100 JCR pharmacy journal was covered by Scopus.

- The impact factor was higher for $\mathbf{8 2}$ and the immediacy index greater for $\mathbf{7 8}$ journals in Scopus in 2005. Pharmacy journals with a high impact factor in the JCR usually have a high impact factor in Scopus.

- Several high but no top-impact journal could be identified in Scopus which were not reported in JCR.

- The two databases differed in the number of articles within a tolerable margin of deviation for most journals.

Keywords: bibliometric analysis; Scopus; Web of Science; Journal Citation Reports; impact factor; immediacy index; comparison of databases; data reliability

\footnotetext{
${ }^{1}$ Correspondence to: Christian Schloegl, Universitaetsstrasse 15/F3, A-8010 Graz, Austria, christian.schloegl@uni-graz.at.
} 
Gorraiz and Schloegl

\section{Introduction}

In 2002, David Adam [1] reported in his article in Nature that the Institute for Scientific Information (ISI) was the undisputed king of the counting houses and the indispensable instrument for scientometric purposes and especially for citation analysis. Adam also foresaw that new software scanning articles, extracting references and automatically generating citation indices may challenge ISI's monopoly shortly after. Late in November 2004 Scopus, a research tool from Elsevier Publishing Company, was commercially launched and claimed to be the "world's largest abstract and indexing database" [2].

The Scopus Web site [3] provides detailed information about the database which has enlisted the collaboration of over 300 researchers world-wide at 21 different institutions for extensive product testing and feedback. In the last two years the product has improved constantly. Scopus has emerged as a dependable research tool providing a user friendly search interface. Furthermore, and even more important, Scopus offers reliable and easy to use citation searching, a feature that until recently has been the exclusive domain of ISI. Actually its new citation tracker has been emulated by its competitor, the Web of Science (WOS), which illustrates the importance and impact this product has gained by now.

There are already several publications which provide more or less extensive evaluations of Scopus with particular emphasis on a comparison with the Web of Science (e. g. Deis \& Goodman [4-5], Gorraiz [6]; Jacso [7], LaGuardia [8], Pipp [9], Schneider [10], Wildner [11]). Just recently, a comprehensive study has been conducted at Utrecht University Library comparing Scopus, Web of Science and Google Scholar with regards to coverage and functionality [12]. However there are only a few studies which focused on the suitability of these citation databases for scientometric analyses.

In their study which analysed citation counts of the Journal of the American Society for Information Science and Technology (JASIST), Bauer and Bakkalbasi [13] found that the Web of Science provided more citation counts to 1985 articles, although this could not be tested statistically. For JASIST articles published in 2000, there was no significant difference between Web of Science and Scopus. Similar results are reported by Jacso [14]. In a recent publication, Ball and Tunger [15] compare the two databases with regard to the number of articles covered, the areas of interest, the number of non-cited articles, and the number of citations of a set of articles. The authors conclude that the outcome of bibliometric analyses may be quite different depending on the database chosen. The identification of such differences was also at the core of the article by Klavans and Boyack [16] who investigated if Scopus and Web of Science generate maps representing the structure of science that are structurally equivalent.

\section{Research questions and methodology}

As already mentioned above, Scopus has emerged as a reliable and easy to use research tool for citation searching. However when it comes up to bibliometric analyses, it seems that Scopus did not yet break the monopoly of its competitor. For this reason, our study aims at examining the suitability of Scopus for bibliometric analyses in comparison with the Web of Science. In particular we want to investigate Scopus and the Web of Science with regard to the following issues:

1. To which extent are high impact JCR (Journal Citation Reports) journals covered by Scopus? Are there journals with a high impact factor which are not included in Scopus?

2. Are the impact factor and the immediacy index usually lower for a JCR journal than the corresponding indicators computed for that journal in the Scopus database?

3. Are there high impact journals not considered by the JCR?

4. How reliable are the data in these two databases? Do the numbers of research and review articles match up in Scopus and JCR?

Since journal indicators like the impact factor and the immediacy index differ among disciplines, we investigated only journals from the subject pharmacy and pharmaceutical sciences. Focussing on one subject 


\section{Gorraiz and Schloegl}

category offers furthermore the possibility to go into more detail when comparing the databases. Though we analysed only pharma journals, our study has also broader implications. Besides revealing all problems involved when comparing two citation databases, it explores the appropriateness of Scopus for bibliometric analyses.

Our original journal sample was derived from the JCR of the year 2005, subject category "pharmacology \& pharmacy". We downloaded the data (impact factor, immediacy index and number of articles published in the year 2005) for the top-100 journals ranked by impact factor and complemented these data with the number of 2003 and 2004 articles (document types article and review) and the number of 2005 citations to 2003, 2004 and 2005 articles.

Since Scopus does not provide any citation statistics comparable to the JCR, we had to retrieve the necessary data from this database manually. But since Scopus has a sophisticated search interface, data collection could be performed with relatively little efforts. When computing the impact factor [for a basic introduction please see 17] and the immediacy index for the Scopus journals, we used the same formulas as in the JCR. Attention has to be paid to the fact that the impact factor (and the immediacy index) only considers research and review articles. As a consequence, we limited our search statements to these document types. In order to determine if there are high impact pharma journals which are not included in the JCR, we used journal lists provided by Science Direct and Subito.

All data were collected in November 2006.

\section{Findings}

The presentation of the results follows the research questions outlined above.

\subsection{Coverage of JCR high impact pharmacology and pharmacy journals in Scopus}

A comparison of journals from a certain subject category between the two databases is not without problems for various reasons. Usually different databases use different classification systems. While the relevant subject category is "pharmacology, toxicology and pharmaceutics" in Scopus, the Web of Science uses two categories ("pharmacology \& pharmacy" and "toxicology"). Furthermore, the different size of the databases must be considered. While there were 193 journals included in the subject category "pharmacology \& pharmacy" (and 75 partly overlapping "toxicology" journals) in the JCR, Scopus covered altogether ${ }^{2} 266$ active titles. (This confirms previous studies [e.g. 2, 7, 12] according to which Scopus has a strong concentration on health and life sciences.) As a consequence, the coverage of JCR journals in Scopus is broader than contrariwise. It was not expected, however, that each of the top-100 JCR pharmacy journals (ranked by impact factor) was included in Scopus.

Finally the indexing procedure is not consistent in different databases. 96 journals were indexed as pharma journals in both citation indices. The remaining four journals were assigned to other categories in Scopus ("medicine" and "biochemistry, genetics and molecular biology").

\footnotetext{
${ }^{2}$ I.e. also pharma journals in subcategories (e.g. "pharmacology (medical)”) of other classes (e.g.“medicine (all)”) were
} considered. 


\section{Gorraiz and Schloegl}

Table 1. Top 100 JCR (2005) journals (subject category “pharmacology \& pharmacy"): impact factor and corresponding values computed in Scopus

\begin{tabular}{|c|c|c|c|c|c|c|c|c|c|c|c|}
\hline \multicolumn{2}{|c|}{ Rank } & \multirow{2}{*}{ Abbrev. journal title } & \multicolumn{3}{|c|}{ Impact factor } & \multicolumn{2}{|c|}{ Rank } & \multirow{2}{*}{ Abbrev. journal title } & \multicolumn{3}{|c|}{ Impact factor } \\
\hline JCR & Scopus & & JCR & Scopus & Diff(\%) & JCR & Scopus & & JCR & Scopus & Diff(\%) \\
\hline 1 & 1 & Annu Rev Pharmacol & 19.833 & 20.813 & $4.9 \%$ & 51 & 50 & Brit J Clin Pharmaco & 2.777 & 3.083 & $11.0 \%$ \\
\hline 2 & 2 & Nat Rev Drug Discov & 18.775 & 17.886 & $5.0 \%$ & 52 & 66 & Behav Pharmacol & 2.773 & 2.646 & $4.8 \%$ \\
\hline 3 & 5 & Rev Physiol Bioch P & 17.053 & 9.824 & $73.6 \%$ & 53 & 48 & \begin{tabular}{|l|} 
Prog Neuro-Psychoph \\
\end{tabular} & 2.769 & 3.221 & $16.3 \%$ \\
\hline 4 & 3 & Pharmacol Rev & 15.689 & 15.958 & $1.7 \%$ & 54 & 52 & Pharm Res & 2.752 & 3.014 & $9.5 \%$ \\
\hline 5 & 4 & \begin{tabular}{|l} 
Trends Pharmacol Sci \\
\end{tabular} & 10.372 & 10.507 & $1.3 \%$ & 55 & 47 & \begin{tabular}{|l|} 
Int Clin Psychopharm \\
\end{tabular} & 2.745 & 3.287 & $19.7 \%$ \\
\hline 6 & 6 & Pharmacol Therapeut & 8.357 & 9.086 & $8.7 \%$ & 56 & 49 & Ther Drug Monit & 2.718 & 3.105 & $14.2 \%$ \\
\hline 7 & 7 & Med Res Rev & 7.964 & 8.636 & $8.4 \%$ & 57 & 57 & Pharmacopsychiatry & 2.620 & 2.846 & $8.6 \%$ \\
\hline 8 & 18 & Drug Discov Today & 7.755 & 5.418 & $43.1 \%$ & 58 & 62 & Toxicology & 2.584 & 2.711 & $4.9 \%$ \\
\hline 9 & 9 & Clin Pharmacol Ther & 7.526 & 7.772 & $3.3 \%$ & 59 & 74 & Neurotoxicology & 2.576 & 2.528 & $1.9 \%$ \\
\hline 10 & 8 & Adv Drug Deliver Rev & 7.189 & 8.144 & $13.3 \%$ & 60 & 56 & \begin{tabular}{|l} 
Eur J Pharm \\
\end{tabular} & 2.525 & 2.876 & $13.9 \%$ \\
\hline 11 & 10 & Drug Resist Update & 6.172 & 7.500 & $21.5 \%$ & 61 & 73 & Comb Chem High T & 2.518 & 2.557 & $1.6 \%$ \\
\hline 12 & 11 & Pharmacogenetics & 5.882 & 6.480 & $10.2 \%$ & 62 & 58 & \begin{tabular}{|l|} 
Life Sci \\
\end{tabular} & 2.512 & 2.806 & $11.7 \%$ \\
\hline 13 & 15 & Curr Drug Metab & 5.416 & 5.805 & $7.2 \%$ & 63 & 61 & Eur J Pharmacol & 2.477 & 2.733 & $10.3 \%$ \\
\hline 14 & 17 & Neuropsychopharmacol & 5.369 & 5.518 & $2.8 \%$ & 64 & 64 & Expert Opin Ther Tar & 2.458 & 2.657 & $8.1 \%$ \\
\hline 15 & 13 & Curr Opin Pharmacol & 5.366 & 5.979 & $11.4 \%$ & 65 & 63 & Int J Antimicrob Ag & 2.428 & 2.687 & $10.7 \%$ \\
\hline 16 & 32 & Antivir Ther & 5.286 & 4.148 & $27.4 \%$ & 66 & 100 & AAPS Pharmsci & 2.417 & 0.983 & $145.8 \%$ \\
\hline 17 & 12 & Clin Pharmacokinet & 5.195 & 6.355 & $22.3 \%$ & 67 & 67 & Invest New Drug & 2.417 & 2.646 & $9.5 \%$ \\
\hline 18 & 36 & Drug Metab Rev & 5.153 & 3.905 & $32.0 \%$ & 68 & 69 & Eur J Pharm SCI & 2.347 & 2.593 & $10.5 \%$ \\
\hline 19 & 14 & J Clin Psychopharm & 5.145 & 5.812 & $13.0 \%$ & 69 & 54 & J Child Adol Psychop & 2.307 & 2.925 & $26.8 \%$ \\
\hline 20 & 21 & Curr Med Chem & 4.904 & 5.210 & $6.2 \%$ & 70 & 70 & Eur J Clin Pharmacol & 2.298 & 2.578 & $12.2 \%$ \\
\hline 21 & 20 & Curr Pharm Design & 4.829 & 5.297 & $9.7 \%$ & 71 & 80 & J Nat Prod & 2.267 & 2.380 & $5.0 \%$ \\
\hline 22 & 19 & Mol Pharmacol & 4.612 & 5.326 & $15.5 \%$ & 72 & 86 & Toxicon & 2.255 & 2.272 & $0.7 \%$ \\
\hline 23 & 16 & Drugs & 4.466 & 5.637 & $26.2 \%$ & 73 & 85 & \begin{tabular}{|l} 
Control Clin Trials \\
\end{tabular} & 2.238 & 2.275 & $1.7 \%$ \\
\hline 24 & 26 & Curr Drug Targets & 4.398 & 4.363 & $0.8 \%$ & 74 & 68 & J Pharm Sci-US & 2.237 & 2.635 & $17.8 \%$ \\
\hline 25 & 22 & Antimicrob Agents Ch & 4.379 & 5.008 & $14.4 \%$ & 75 & 84 & Cancer Chemoth & 2.235 & 2.278 & $1.9 \%$ \\
\hline 26 & 27 & J Pharmacol Exp Ther & 4.098 & 4.345 & $6.0 \%$ & 76 & 81 & \begin{tabular}{|l|} 
Peptides \\
\end{tabular} & 2.231 & 2.348 & $5.2 \%$ \\
\hline 27 & 31 & Drug Metab Dispos & 4.015 & 4.157 & $3.5 \%$ & 77 & 65 & Pharmacoeconomics & 2.198 & 2.651 & $20.6 \%$ \\
\hline 28 & 24 & Psychopharmacology & 3.994 & 4.438 & $11.1 \%$ & 78 & 99 & Drug News Perspect & 2.159 & 1.677 & $28.7 \%$ \\
\hline 29 & 34 & Pharmacogenomics J & 3.989 & 4.010 & $0.5 \%$ & 79 & 77 & Int J Pharm & 2.156 & 2.461 & $14.1 \%$ \\
\hline 30 & 42 & Int J Neuropsychoph & 3.981 & 3.570 & $11.5 \%$ & 80 & 92 & Cardiovasc Drug Rev & 2.122 & 2.082 & $1.9 \%$ \\
\hline 31 & 25 & J Antimicrob Chemoth & 3.886 & 4.402 & $13.3 \%$ & 81 & 89 & N-S Arch Pharmacol & 2.098 & 2.178 & $3.8 \%$ \\
\hline 32 & 33 & Curr Opin Drug Disc & 3.778 & 4.093 & $8.3 \%$ & 82 & 71 & Pharmacol Res & 2.096 & 2.574 & $22.8 \%$ \\
\hline 33 & 29 & Crit Rev Ther Drug & 3.696 & 4.280 & $15.8 \%$ & 83 & 94 & \begin{tabular}{|l|} 
Chirality \\
\end{tabular} & 2.072 & 2.018 & $2.7 \%$ \\
\hline 34 & 30 & J Control Release & 3.696 & 4.217 & $14.1 \%$ & 84 & 55 & Drug Aging & 2.072 & 2.923 & $41.1 \%$ \\
\hline 35 & 28 & CNS Drugs & 3.671 & 4.318 & $17.6 \%$ & 85 & 72 & Microb Drug Resist & 2.072 & 2.559 & $23.5 \%$ \\
\hline 36 & 35 & Neuropharmacology & 3.637 & 3.958 & $8.8 \%$ & 86 & 79 & \begin{tabular}{|l|} 
Biomed Pharmacother \\
\end{tabular} & 2.069 & 2.386 & $15.3 \%$ \\
\hline 37 & 59 & Pharmacogenomics & 3.623 & 2.794 & $29.7 \%$ & 87 & 87 & Assay Drug Dev & 2.060 & 2.198 & $6.7 \%$ \\
\hline 38 & 38 & Biochem Pharmacol & 3.617 & 3.829 & $5.9 \%$ & 88 & 82 & \begin{tabular}{|l} 
J Pharm Pharm Sci \\
\end{tabular} & 2.042 & 2.324 & $13.8 \%$ \\
\hline 39 & 60 & Eur Neuropsychopharm & 3.510 & 2.760 & $27.2 \%$ & 89 & 88 & Int Immunopharmacol & 2.008 & 2.183 & $8.7 \%$ \\
\hline 40 & 23 & Aliment Pharm Therap & 3.434 & 4.891 & $42.4 \%$ & 90 & 91 & Pharmacol Biochem & 1.970 & 2.102 & $6.7 \%$ \\
\hline 41 & 40 & Int J Immunopath Ph & 3.418 & 3.769 & $10.3 \%$ & 91 & 90 & Chem-Biol Interact & 1.968 & 2.141 & $8.8 \%$ \\
\hline 42 & 43 & Brit J Pharmacol & 3.410 & 3.546 & $4.0 \%$ & 92 & 97 & \begin{tabular}{|l|} 
Exp Clin \\
\end{tabular} & 1.952 & 1.882 & $3.7 \%$ \\
\hline 43 & 41 & Antivir Res & 3.406 & 3.703 & $8.7 \%$ & 93 & 75 & Pharmacotherapy & 1.920 & 2.486 & $29.5 \%$ \\
\hline 44 & 53 & CNS Drug Rev & 3.353 & 2.953 & $13.5 \%$ & 94 & 96 & \begin{tabular}{|l|} 
Anti-Cancer Drug \\
\end{tabular} & 1.907 & 1.977 & $3.6 \%$ \\
\hline 45 & 45 & Expert Opin Inv Drug & 3.267 & 3.479 & $6.5 \%$ & 95 & 76 & \begin{tabular}{|l|} 
Clin Neuropharmacol \\
\end{tabular} & 1.890 & 2.466 & $30.5 \%$ \\
\hline 46 & 37 & Drug Safety & 3.211 & 3.885 & $21.0 \%$ & 96 & 93 & Hum Psychopharm & 1.890 & 2.025 & $7.2 \%$ \\
\hline 47 & 51 & J Psychopharmacol & 3.178 & 3.037 & $4.6 \%$ & 97 & 95 & J Pharmaceut Biomed & 1.889 & 1.984 & $5.0 \%$ \\
\hline 48 & 46 & Toxicol Appl Pharm & 3.148 & 3.340 & $6.1 \%$ & 98 & 78 & Ann Pharmacother & 1.837 & 2.420 & $31.8 \%$ \\
\hline 49 & 39 & Clin Ther & 3.030 & 3.776 & $24.6 \%$ & 99 & 98 & Qsar Comb Sci & 1.826 & 1.850 & $1.3 \%$ \\
\hline 50 & 44 & J Clin Pharmacol & 2.889 & 3.514 & $21.6 \%$ & 100 & 83 & \begin{tabular}{|l} 
Expert Opin \\
\end{tabular} & 1.823 & 2.300 & $26.2 \%$ \\
\hline
\end{tabular}




\section{Gorraiz and Schloegl}

\subsection{Differences in impact factor and immediacy index}

Since there are more journals included in Scopus than in WOS, a journal in Scopus has a higher chance to get cited in general. Therefore the values for the impact factor and the immediacy index should also be higher in Scopus. This assumption turned out to be true for most journals in our journal sample. The impact factor was higher for 82 journals in Scopus, 18 journals had a higher impact factor in the JCR. Similarly the immediacy index of 78 journals had higher values in Scopus. As can be seen in Table 1, a journal with a high impact factor in the JCR usually has a high impact factor in Scopus, and vice versa. This goes along with the correlation (Pearson's $\mathrm{r}=0.96$ ) of the impact factors of the top-100 pharma journals in the JCR and those computed for them in Scopus.

The size of the differences (in \%) between the impact factor values follows a skewed distribution (see Table 2). For most journals, the difference is relatively small (median $=10.3 \%$ ). Yet two journals ("Reviews of Physiology Biochemistry and Pharmacology" and "AAPS Pharmsci”) attracted our attention because of their remarkable discrepancies of 74 and 146 percent. A first analysis shows that these big differences are not only caused by different citation frequencies but also by high deviations in the numbers of articles. In order to identify the reasons for these differences, we will go into deeper analysis in the following sub-section (reliability of data).

Table 2. Distribution of the \% differences between Scopus and JCR in the impact factor, immediacy index, number of articles in 2003, 2004 and 2005, and the number of 2005 citations to articles from those years (basis for comparison: top-100 JCR pharma journals ranked by impact factor)

\begin{tabular}{|c|c|c|c|c|c|c|c|c|}
\hline & \multirow{2}{*}{$\begin{array}{l}\text { Impact } \\
\text { factor }\end{array}$} & \multirow{2}{*}{$\begin{array}{c}2003 \\
\text { articles }\end{array}$} & \multirow{2}{*}{$\begin{array}{c}2004 \\
\text { articles }\end{array}$} & \multicolumn{3}{|c|}{2005 citations to } & \multirow{2}{*}{$\begin{array}{c}2005 \\
\text { articles }\end{array}$} & \multirow{2}{*}{$\begin{array}{l}\text { Immediacy } \\
\text { index }\end{array}$} \\
\hline & & & & 03’art. & 04'art. & 05'art. & & \\
\hline \multicolumn{9}{|l|}{ Differences between } \\
\hline \multicolumn{9}{|l|}{ Scopus and JCR } \\
\hline $0-5 \%$ & 25 & 71 & 68 & 21 & 15 & 6 & 66 & 7 \\
\hline $5-10 \%$ & 23 & 10 & 11 & 28 & 20 & 7 & 10 & 8 \\
\hline $10-20 \%$ & 28 & 7 & 11 & 32 & 35 & 20 & 10 & 24 \\
\hline $20-30 \%$ & 16 & 7 & 5 & 13 & 18 & 25 & 2 & 25 \\
\hline $30-50 \%$ & 6 & 2 & 2 & 5 & 11 & 24 & 5 & 19 \\
\hline$>=50 \%$ & 2 & 3 & 3 & 1 & 1 & 16 & 4 & 14 \\
\hline Total & 100 & 100 & 100 & 100 & 100 & 98 & 97 & 97 \\
\hline Median (of \% differences) & $10.3 \%$ & $2.1 \%$ & $2.1 \%$ & $10.5 \%$ & $14.4 \%$ & $24.5 \%$ & $1.6 \%$ & $23.4 \%$ \\
\hline $\begin{array}{l}\text { No. of journals with } \\
\text { greater values in Scopus } \\
\text { No. of journals with }\end{array}$ & 82 & 65 & 65 & 86 & 94 & 86 & 66 & 78 \\
\hline greater values in JCR & 18 & 14 & 17 & 13 & 6 & 10 & 11 & 18 \\
\hline
\end{tabular}

Table 2 also confirms the original assumption that higher citations in Scopus, which are generated by more (pharma) journals in this database, are the main cause for the higher impact factor values. The median of the percentage differences between Scopus and the JCR in the impact factor (10.3\%) is similar to those in the 2005 citations to articles published in 2003 (10.5\%) and 2004 (14.4\%). (Hence, it would be worth considering to normalize the impact factor values in order to allow a "fair" comparison.)

The higher differences in the immediacy index (median $=23.4 \%$ ) are also mainly due to greater deviations in the number of citations which articles published in 2005 have received in the same year (median = $24.5 \%$ ). However, it must be taken into account that, because the number of citations in the year in which these articles were published is low in general, already small deviations in the absolute numbers can show high percentage effects. As was pointed out by one of the referees, "Molecular Pharmacology" is an extreme example. The reason 


\section{Gorraiz and Schloegl}

for the huge difference in the immediacy index for this journal (nearly 8800\% - see Table 3) is due to an error in the JCR. While a search in WOS showed 413 citations in the year 2005 to articles published in the same year, the JCR lists only 6 citations. As a consequence, the immediacy index ought to be corrected to 0.93 in the JCR resulting in a much smaller difference in comparison with the corresponding value computed in Scopus.

Table 3. Top 50 JCR (2005) journals (subject category “pharmacology \& pharmacy”) ranked by impact factor: immediacy index and corresponding values computed in Scopus

\begin{tabular}{|c|c|c|c|c|c|c|c|c|c|}
\hline \multirow{2}{*}{$\begin{array}{c}\text { Rank } \\
\text { JCR }\end{array}$} & \multirow{2}{*}{ Abbrev. journal title } & \multicolumn{3}{|c|}{ Immediacy index } & \multirow{2}{*}{$\begin{array}{c}\text { Rank } \\
\text { JCR }\end{array}$} & \multirow{2}{*}{ Abbrev. journal title } & \multicolumn{3}{|c|}{ Immediacy index } \\
\hline & & JCR & Scopus & $\operatorname{Diff}(\%)$ & & & JCR & Scopus & Diff(\%) \\
\hline 1 & Annu Rev Pharmacol & 5.793 & 7.172 & $23.8 \%$ & 26 & J Pharmacol Exp Ther & 0.891 & 1.072 & $20.3 \%$ \\
\hline 2 & Nat Rev Drug Discov & 3.364 & 2.574 & $30.7 \%$ & 27 & Drug Metab Dispos & 0.733 & 0.787 & $7.4 \%$ \\
\hline 3 & Rev Physiol Bioch P & 0.214 & 0.600 & $180.4 \%$ & 28 & Psychopharmacology & 0.4 & 0.768 & $92.0 \%$ \\
\hline 4 & Pharmacol Rev & 1.586 & 1.724 & $8.7 \%$ & 29 & Pharmacogenomics J & 1.136 & 1.277 & $12.4 \%$ \\
\hline 5 & Trends Pharmacol Sci & 1.951 & 2.054 & $5.3 \%$ & 30 & Int J Neuropsychoph & 0.912 & 1.103 & $21.0 \%$ \\
\hline 6 & Pharmacol Therapeut & 1 & 1.193 & $19.3 \%$ & 31 & J Antimicrob Chemoth & 0.749 & 0.888 & $18.5 \%$ \\
\hline 7 & Med Res Rev & 1.552 & 1.862 & $20.0 \%$ & 32 & Curr Opin Drug Disc & 0.662 & 0.848 & $28.2 \%$ \\
\hline 8 & Drug Discov Today & 1.125 & 1.287 & $14.4 \%$ & 33 & Crit Rev Ther Drug & 0.333 & 0.545 & $63.8 \%$ \\
\hline 9 & Clin Pharmacol Ther & 1.689 & 1.243 & $35.9 \%$ & 34 & J Control Release & 0.429 & 0.479 & $11.7 \%$ \\
\hline 10 & Adv Drug Deliver Rev & 1.176 & 1.520 & $29.3 \%$ & 35 & CNS Drugs & 0.736 & 1.000 & $35.9 \%$ \\
\hline 11 & Drug Resist Update & 0.227 & 0.556 & $144.7 \%$ & 36 & Neuropharmacology & 0.552 & 0.692 & $25.4 \%$ \\
\hline 12 & Pharmacogenetics & - & - & - & 37 & Pharmacogenomics & 0.444 & 0.380 & $16.9 \%$ \\
\hline 13 & Curr Drug Metab & 0.425 & 0.500 & $17.6 \%$ & 38 & Biochem Pharmacol & 0.489 & 0.556 & $13.7 \%$ \\
\hline 14 & Neuropsychopharmac & 1.181 & 1.421 & $20.3 \%$ & 39 & Eur Neuropsychopharm & 1.215 & 1.488 & $22.5 \%$ \\
\hline 15 & Curr Opin Pharmacol & 0.854 & 1.178 & $37.9 \%$ & 40 & Aliment Pharm Therap & 0.578 & 0.732 & $26.6 \%$ \\
\hline 16 & \begin{tabular}{|l|} 
Antivir Ther \\
\end{tabular} & 0.642 & 0.626 & $2.6 \%$ & 41 & Int J Immunopath Ph & 0.341 & 0.358 & $5.0 \%$ \\
\hline 17 & Clin Pharmacokinet & 0.723 & 1.096 & $51.6 \%$ & 42 & Brit J Pharmacol & 0.541 & 0.646 & $19.5 \%$ \\
\hline 18 & Drug Metab Rev & 0.55 & 0.476 & $15.5 \%$ & 43 & Antivir Res & 0.473 & 0.627 & $32.5 \%$ \\
\hline 19 & \begin{tabular}{|l|} 
J Clin Psychopharm \\
\end{tabular} & 0.824 & 1.022 & $24.0 \%$ & 44 & CNS Drug Rev & 0.235 & 0.222 & $5.8 \%$ \\
\hline 20 & Curr Med Chem & 0.542 & 0.605 & $11.5 \%$ & 45 & Expert Opin Inv Drug & 0.354 & 0.504 & $42.3 \%$ \\
\hline 21 & Curr Pharm Design & 1.194 & 1.418 & $18.7 \%$ & 46 & Drug Safety & 0.646 & 0.938 & $45.2 \%$ \\
\hline 22 & Mol Pharmacol & 0.014 & 1.245 & $8796 \%$ & 47 & J Psychopharmacol & 0.434 & 0.500 & $15.2 \%$ \\
\hline 23 & Drugs & 0.677 & 0.952 & $40.6 \%$ & 48 & Toxicol Appl Pharm & 0.506 & 0.487 & $3.9 \%$ \\
\hline 24 & \begin{tabular}{|l|} 
Curr Drug Targets \\
\end{tabular} & 0.305 & 0.463 & $51.9 \%$ & 49 & Clin Ther & 0.241 & 0.325 & $35.0 \%$ \\
\hline 25 & Antimicrob Agents Ch & 0.82 & 0.984 & $20.0 \%$ & 50 & J Clin Pharmacol & 0.578 & 0.711 & $23.1 \%$ \\
\hline
\end{tabular}

\subsection{Reliability of data}

Contrary to the citations received, there should be only small differences in the number of articles between the two databases. Since Pipp [9, p. 13] reported differences in the provision of document types between the two databases which may strongly affect the number of retrieved records, we considered only articles and review articles. As can be seen in Table 2, the values for the median of the percentage differences are between 1.6 and $2.1 \%$ in the three years. The difference in the number of research and review articles is below $5 \%$ for two thirds of all journals in each year. Nevertheless, we computed a wider difference of at least 10 percent for one fifth of all journals. There were even a few journals in each year, in which the article counts differed more than 50\% (2003: "Reviews of Physiology Biochemistry and Pharmacology“, "Pharmacogenomics”, "Drug Discovery Today”, 2004: "Reviews of Physiology, Biochemistry and Pharmacology“, "Drug News \& Perspectives”, "AAPS Pharmsci”, 2005: "Nature Reviews Drug Discovery”, “CNS Drug Reviews”, “European Journal of Pharmaceutical Sciences”, "Drug News \& Perspectives”). This raises severe questions with regard to data quality. 


\section{Gorraiz and Schloegl}

Table 4: "Reviews of Physiology, Biochemistry and Pharmacology": number of review articles according to journal, JCR, WOS, and Scopus

\begin{tabular}{lccc}
\hline & 2003 & 2004 & 2005 \\
\hline $\begin{array}{l}\text { No. of articles (data collected } \\
\text { from journal volumes) }\end{array}$ & 20 & 14 & 10 \\
No. of articles indexed in & & & \\
$\quad$ JCR & 8 & 11 & 14 \\
$\quad$ Web of Science & 8 & 11 & 21 \\
$\quad$ Scopus & 20 & 14 & 10 \\
\hline
\end{tabular}

In the following, we go into more details about the discrepancies of the two journals identified in the previous section. As is revealed by Table 4, the article counts in Scopus are accordant with the real values we collected for "Reviews of Physiology, Biochemistry and Pharmacology". However, there are big deviations in the article numbers for this hybrid serial in comparison with the Web of Science. The main reason for this mismatch might be the irregular publication of this serial. Accordingly, a few volumes were not indexed in the proper publication year in WOS. As can also be seen in Table 4, there are again data inconsistencies between JCR and WOS for the year 2005.

Table 5: "AAPS Pharmsci” and "AAPS Journal”: number of articles and review articles according to journal homepage, JCR, WOS, and Scopus

\begin{tabular}{lcccc}
\hline & $\begin{array}{c}2003 \\
\text { AAPS PharmSCI }\end{array}$ & $\begin{array}{c}2004 \\
\text { AAPS }\end{array}$ & $\begin{array}{c}2005 \\
\text { AAPS J }\end{array}$ \\
\hline $\begin{array}{l}\text { No. of articles (data collected } \\
\text { from journal homepage) }\end{array}$ & 32 & 14 & 19 & 83 \\
$\begin{array}{l}\text { No. of articles indexed in } \\
\text { JCR }\end{array}$ & & & & \\
Web of Science & 22 & 14 & 20 & 83 \\
Scopus & 31 & 14 & 20 & 83 \\
\hline
\end{tabular}

For the electronic journal “AAPS PharmSCI” (see Table 5) the JCR article data of the year 2003, which are used for the calculation of the impact factor, are again erroneous (22 instead of 32 articles) and not consistent with the WOS figures (31 articles). However, the indexing in JCR and WOS is nearly correct in the following years. Contrary to WOS, the title change (from “AAPS PharmSCI” to “AAPS J”) affected Scopus more negatively. In particular it is not very clear which articles refer to which journal title. For instance, a search for the former title (“AAPS PharmSCI”) in 2005 shows 76 articles and review articles assigned to “AAPS J”. However, a search for "AAPS J" in the same year lists only one article for this title (but 48 items for "AAPS Journal Electronic Resource”).

For most other journals, the mismatch in the article counts was due to the different assignment to document types. For instance, various conference papers in "Drug Discovery Today", "Drug News \& Perspectives" and "CNS Drug Reviews" were categorized as articles in Scopus; in WOS they were nonexistent. For two other journals ("Nature Reviews Drug Discovery" and "Pharmacogenomics") opinion papers were attributed to articles in Scopus but to editorial comments in WOS. And in the "European Journal of Pharmaceutical Sciences" meeting abstracts were wrongly assigned to articles in Scopus. As this short analysis reveals, both Scopus and WOS have problems with regard to the accuracy of data. Unlike Deis and Goodman [4, 5], our analysis suggests that Scopus is not worse than the Web of Science with regard to the completeness of (research and review) articles in journals. It must be considered, however, that our analysis was based on a small, more specialized and more present journal sample. 


\subsection{Pharmaceutical journals covered by Scopus but not included in the JCR}

In order to identify other high impact pharmaceutical journals not covered by the JCR, it would be easiest to compare the highest impact journals in Scopus with their counterparts in JCR. Though Scopus offers sophisticated tools for citation analysis, there are no citation statistics and rankings comparable with the JCR in this database as of now. As a consequence, the compilation of the high impact journals in this database can be rather laborious and time-consuming. For this reason we contacted Elsevier which provided us with the citation counts and number of articles for journals from the subject category "pharmacology, toxicology and pharmaceutical science" in Science Direct. After having checked the reliability of data for these 81 journals in Scopus (in case of data inconsistencies we used the Scopus data), we calculated the impact factor and the immediacy index and compared them with the results in JCR.

Table 6. Presence and absence of Science Direct journals (subject category "pharmacology, toxicology and pharmaceutical science”) in JCR

\begin{tabular}{|c|c|c|c|c|}
\hline & \multirow{2}{*}{$\begin{array}{c}\text { No. of } \\
\text { journals }\end{array}$} & \multirow{2}{*}{$\begin{array}{l}\text { Particular top impact journal in } \\
\text { Science Direct }\end{array}$} & \multicolumn{2}{|c|}{ Impact factor } \\
\hline & & & Scopus & JCR \\
\hline Not included in the JCR & 10 & NeuroRX & 2.261 & - \\
\hline \multicolumn{5}{|l|}{ Included in JCR: } \\
\hline Subject pharmacology and pharmacy & 40 & $\begin{array}{l}\text { Trends in Pharmacological } \\
\text { Sciences }\end{array}$ & 10.504 & 10.372 \\
\hline Subject toxicology & 10 & Critical Reviews in Toxicology & 5.233 & 5.000 \\
\hline Other subject categories & 21 & Pain & 5.129 & 4.309 \\
\hline Total no. of Science Direct journals & 81 & & & \\
\hline
\end{tabular}

As can be seen in Table 6, 10 out of 81 titles were not covered by JCR in the year 2005. For each of these journals, we computed a relatively low impact factor. Only one Science Direct journal ("NeuroRX"), with an impact factor amounting to 2.261, would place in the JCR top 100 ranking. For four titles ("Acute Pain”, "The American Journal of Geriatric Pharmacotherapy”, “Journal of Clinical Forensic Medicine” and "Legal Medicine”) an impact factor was calculated which would rank these journals better than the worst ranked (193rd) JCR pharma journal. The impact factor of the other five journals could not be computed because of publication or indexing irregularities.

From the remaining 71 journals, 40 were covered under the subject categories "pharmacology and pharmacy", 10 under "toxicology" and 21 under other categories such as "medicine” in JCR. 31 of the 40 titles were among the JCR top 100 pharma journals, i.e. almost one third of the JCR top 100 pharmaceutical journals are currently published by Elsevier and are available in full text via Science Direct. Four of these journals are in the top 10, with "Trends in Pharmacological Sciences" ranked best in fifth position. Comparing the impact factors between Scopus and JCR revealed again that most journals have a higher value for this indicator in the Scopus database. Also the distribution of the differences (in percent) is similar.

In order to determine further "candidates" for important journals, we tied up to the results of a study by Schloegl and Gorraiz [18] which showed a low to moderate correlation between the journal requests at a document delivery service and the citation frequencies of those journals in the JCR. Accordingly, we used data from Subito [19], one of the largest European document delivery services, and examined highly demanded journals for inclusion in JCR and Scopus. Our comparison revealed that from the top 100 JCR journals (subject category "pharmacology and pharmacy") 60 titles were among the 1000 most requested journals in Subito. Furthermore, we identified three Subito journals ("Current Pharmaceutical Biotechnology", "Pediatric Drugs", and "Expert Opinion on Drug Safety") which were included in Scopus but not in JCR. The computed impact factors in Scopus amounted to 2.578, 2.188 and 1.798. This would place them 59th, 78th and 103rd in the JCR ranking. 


\section{Gorraiz and Schloegl}

\section{Conclusions}

The most relevant implications of our study can be resumed as follows:

Coverage:

Our analysis showed that both WOS and Scopus have a good coverage of high impact journals in the field of pharmacology and pharmacy. We could identify a few pharmaceutical journals with a significant but not top impact factor which were not included in the JCR. We computed higher values for both impact factor and immediacy index for most journals in Scopus. This is mainly due to the fact that there are more sources in Scopus which generate higher citations in this database and confirms that Scopus is the world's largest multidisciplinary database in terms of more recent scholarly literature (the back files of the Web of Science go back much further to the past).

\section{Subject categories:}

The subject categorisation is not very extensive in either database. Furthermore, the assignment of subject categories to journals is not always transparent and differs between Scopus and WOS. This can lead to more or less considerable differences when comparing the two databases. Obviously, a more detailed subject categorisation and a better journal classification would improve the quality of the two databases.

\section{Document types:}

Another implication of our study is that Scopus and the Web of Science provide different document types and that they do not assign them always consistently. As our analysis has shown, a different assignment to document types was one of the main reasons for mismatches in the number of (research) articles.

\section{Reliability of data:}

The differences in the number of research and review articles were tolerable for the majority of the investigated journals. Nevertheless, we calculated greater differences for several journals which were caused by both Scopus and WOS. Furthermore, data consistency between WOS and JCR cannot be taken for granted. In cases where data accuracy is crucial, it is advisable to verify the data.

Appropriateness for bibliometric analyses:

In our study, Scopus turned out to be suitable for bibliometric analyses. However, the practicability of such studies could be much increased if Scopus were to add an own bibliometric "infrastructure" comparable to the Journal Citation Reports to its citation database. Since such an add-on could be implemented from scratch, critical issues concerning the JCR could be avoided from the beginning. Among other issues [see e.g. 20], this applies to field-normalized journal impact indicators [e.g. 21, p. 1993f.]. Furthermore, it could be avoided to mix different document types when relating the citation frequencies to the article counts [e.g. 22,23]. Concerning conference articles, Scopus is more transparent than the Web of Knowledge. For the latter it is not always clear in which cases proceedings, which are recorded in ISI Proceedings in general, are included.

\section{Acknowledgments}

The authors would like to thank Ms. Helen J. de Mooij and Mr. Camiel Gielkens from Elsevier for data provision, Prof. John Cawood from the Department of Information and Communications at Manchester Metropolitan University for proof-reading, and the referees for their valuable comments.

\section{References}

D. Adam, The counting house, Nature 415, 14.2.2002 (2006), 726-729. 
[2] H.M. Dess, Scopus, Issues in Science and Technology Librarianship 45, Winter, (2006). Available at: http://www.istl.org/06-winter/databases4.html (accessed 10 May 2007).

[3] Scopus, Scopus Info. Available at: http://www.info.scopus.com (accessed 10 May 2007).

[4] H.F. Deis and D. Goodman, Web of Science (2004 version) and Scopus, The Charleston Advisor 6(3) (2005). Available at: http://www.charlestonco.com/comp.cfm?id=43 (accessed 10 May 2007).

[5] H.F. Deis and D. Goodman, Update on Scopus, The Charleston Advisor 7(3) (2006). Available at: http://www.charlestonco.com/comp.cfm?id=55 (accessed 10 May 2007).

[6] J. Gorraiz, Web of Science versus Scopus oder das aktuelle Dilemma der Bibliotheken. [Web of Science versus Scopus or the current dilemma of libraries], Mitteilungen der Vereinigung Osterreichischer Bibliothekarinnen und Bibliothekare 59(1) (2006), 25-30.

[7] P. Jacso, As we may search: Comparison of major features of the Web of Science, Scopus, and Google Scholar citation-based and citation-enhanced databases, Current Science 89(9) (2005), 1537-1547. Available at: http://www.ias.ac.in/currsci/nov102005/1537.pdf (accessed 10 May 2007).

[8] C. LaGuardia, E-Views and reviews: Scopus vs Web of Science, Library Journal.com, January 15th (2005). Available at: http://www.libraryjournal.com/article/CA491154.html\%22 (accessed 10 May 2007).

[9] E. Pipp, Inhaltlicher Vergleich von Web of Science und Scopus an Hand der erfassten Zeitschriften. [Comparison of the contents of Scopus and Web of Science by means of journal coverage], Mitteilungen der Vereinigung Österreichischer Bibliothekarinnen und Bibliothekare 59(1) (2006), 3-18.

[10] K. Schneider, Scopus - Web of Science: Versuch einer Bewertung aus pharmakognostischer Sicht. [Scopus - Web of Science: attempt of an assessment from a pharmacognostic view], Mitteilungen der Vereinigung Österreichischer Bibliothekarinnen und Bibliothekare 59(1) (2006, 21-24.

[11] B. Wildner, Web of Science - Scopus: Auf der Suche nach Zitierungen. [Web of Science - Scopus: Looking for citations], Mitteilungen der Vereinigung Österreichischer Bibliothekarinnen und Bibliothekare 59(1) (2006), 18-20.

[12] J. Bosman, I. van Mourik, M. Rasch, E. Sieverts and H. Verhoeff, Scopus reviewed and compared: The coverage and functionality of the citation database Scopus, including comparisons with Web of Science and Google Scholar (Universiteitsbibliotheek Utrecht, Utrecht 2006). Available at: http://igiturarchive.library.uu.nl/DARLIN/2006-1220-200432/Scopus\%20doorgelicht\%20\&\%20vergeleken\%20\%20translated.pdf (accessed 10 May 2007).

[13] Bauer, K. and N. Bakkalbasi, An examination of citation counts in a new scholarly communication environment, D-Lib Magazine 11(9) (2005). Available at: http://www.dlib.org/dlib/september05/bauer/09bauer.html (accessed 10 May 2007).

[14] P. Jacso, Evaluation of citation enhanced scholarly databases, Journal of Information Processing \& Management 48(12) (2006), 763-774.

[15] R. Ball and D. Tunger, Science indicators revisited - Science Citation Index versus Scopus: A bibliometric comparison of both citation databases, Information Services \& Use 26(4) (2006), 293-301.

[16] R. Klavans and K.W. Boyack, Is there a convergent structure of science? A comparison of maps using the ISI and Scopus databases. In: D. Torres-Salinas and H.F. Moed (ed.), Proceedings of ISSI 2007, vol. 1, (CSIC, Madrid, 2007), 437-448.

[17] E. Garfield, The impact factor, Current Contents, (25) 20 June 1994, 3-7. Available at: http://scientific.thomson.com/free/essays/journalcitationreports/impactfactor/ (accessed 23 October 2007).

[18] C. Schloegl and J. Gorraiz, Document delivery as a source for bibliometric analyses: the case of Subito, Journal of Information Science 32(3) (2006), 223-237.

[19] Subito, Dokumente aus Bibliotheken e.V. Available at: http://www.subito-doc.de/ (accessed 10 May 2007).

[20] W.G. Stock, Journal Citation Reports: Ein Impact Faktor für Bibliotheken, Verlage und Autoren? [An impact factor for libraries, publishers and authors?], Password (5) (2001), 24-39. 
Gorraiz and Schloegl

[21] H. Moed, Citation analysis of scientific journals and journal impact measures, Current Science 89(12) (2005), 1990-1996.

[22] P. Jasco, A deficiency in the algorithm for calculating the impact factor of scholarly journals: The journal impact factor, Cortex 37(4) (2001), 590-594. Available at: http://www.jacso.info/PDFs/jacso-cortex-590594.pdf (accessed 23 October 2007).

[23] P. Jasco, The number game, Online Information Review 24(2) (2000), 180-183. Available at: http://www.jacso.info/PDFs/jacso-numbergame.PDF (accessed 23 October 2007). 